\title{
“Ó VÓS QUE ENTRAIS PERDEI TODA A ESPERANÇA.” A ESTÉTICA DA RESISTÊNCIA NO CINEMA ARGENTINO
}

\section{Neiva Maria Mallmann Graziadei ${ }^{1}$}

RESUMO: Este artigo pretende abordar o conceito de resistência em cinco filmes produzidos durante a última ditadura cívico-militar na Argentina ocorrida entre os anos de 1970 e 1980. Não obstante o final dessa, o período ainda provoca, no meio intelectual e restante dos argentinos em geral, reações estéticas contrárias àquele regime. Minha hipótese é de que os filmes, La historia oficial (1985) La noche de los lápices (1986), Garage Olimpo (1999), Kamchatka (2002) e Kóblic (2016) aqui analisados, resultam de uma memória aberta e muito presente na filmografia argentina, numa clara atitude de resistência à ditadura como também às tentativas de apagamento da memória.

Palavras-chave: resistência; memória; filmografia; ditadura; Argentina.

\begin{abstract}
This article aims at approaching the concept of resistance as it is portrayed in five movies produced throughout the civil-military dictatorship in Argentina and which took place in the 1970s and 1980s. Despite its ending, this period still causes, in the intellectual and in other Argentinian sectors in general, aesthetic reactions which are contrary to the one followed by the regime. My hypothesis is that the movies, La historia oficial (1985), La noche de los lápices (1986), Garage Olimpo (1999), Kamchatka (2002) and Kóblic (2016) which will be analysed throughout the text, result from an open and very present memory in the Argentinian movie industry, in a clear attitude of resistance not only to the dictatorship itself but also to the attempts to erase memories.
\end{abstract}

Keywords: resistance; memory; filmography; dictatorship; Argentina.

O título desse artigo remete ao Canto III da Divina Comédia quando Dante se assombra com a inscrição no portal do Inferno, no original: lasciate ogne speranza, voi ch'intrate. O poema se atualiza quando nos valemos de seu sentido trágico ao tratar da produção cinematográfica argentina, a partir dos anos 70 até o momento, como uma forma de resistência à negação de uma das mais violentas ditaduras do Cone Sul.

A concepção de resistência alia-se ao de memória em razão de que, quando se resiste a algo, é porque conhecemos este algo e em consequência, somos passíveis de recordá-lo ou esquecê-lo, segundo o pensamento fenomenológico de Paul Ricoeur $(2008$, p.19) de que "toda conciencia es conciencia de algo". Ou, ainda em suas palavras, "no tenemos otro recurso, sobre la referencia al pasado, que la memoria misma" (p.40). Isso significa que memória e conhecimento são indispensáveis um ao outro. No caminho inverso, manter-se viva uma memória sobre algo que ocorreu e, propositalmente, fazer-se algo que evite o esquecimento, é também uma forma de memória.

Seu conceito multifacetado nos permite compreender que, dentre os muitos vieses sobre os quais se apresenta a memória, o pensamento de Pierre Nora é fundamental para a sequência de nossa conversa:

\begin{abstract}
A memória é vida (...) aberta à dialética da lembrança e do esquecimento (...). Porque é afetiva e mágica, a memória não se acomoda a detalhes que a confortam; ela se alimenta de lembranças vagas, telescópicas, globais ou flutuantes, particulares ou simbólicas, sensível a todas as cenas, censura ou projeções (...) a memória emerge de um grupo que ela une (...) como Halbwachs o fez, que há tantas memórias quanto grupos existem; que ela é por natureza, múltipla e desacelerada, coletiva, plural e
\end{abstract}

\footnotetext{
${ }^{1}$ Professora de Língua Espanhola do Curso de Letras Licenciatura Português e Espanhol do Campus Cerro Largo, RS, da Universidade Federal da Fronteira Sul, UFFS. E-mail: neivag53@ gmail.com.
} 
individualizada (...) a memória se enraíza no concreto, no espaço, no gesto, na imagem, no objeto. (NORA, 1993, p.9)

Bem, quanto ao conceito de resistência, ele é tão múltiplo quanto o é o da memória, servindo a todos os campos do saber, expresso de forma individual ou coletiva. Alfredo Bosi (2002) o tem como "(...) um conceito ético, e não estético. O seu sentido mais profundo apela para a força de vontade que resiste a outra força, exterior ao sujeito. Resistir é opor a força própria à força alheia" (p.118).

Considerando o pensamento de Benedetto Croce, que distingue arte de ética e política, o autor argumenta que resistência e estética podem não ser excludentes entre si quando, segundo suas palavras, "a) a resistência se dá como tema" b) a resistência se dá como processo inerente à escrita" (p.120). Portanto, resistência é uma das alternativas que o ser humano lança mão ao desempenhar seus múltiplos papéis em uma sociedade, como transgressão ao poder dominante, seja ele político ou midiático.

Bosi propõe um caminho no qual a resistência aconteça como tema; dito com outras palavras, aquele que tem a responsabilidade de zelar pelos valores éticos de uma sociedade, compromete-se também a uma reflexão sobre seus desvalores: “O homem de ação, o educador ou o político que interfere diretamente na trama social, julgando-a e, não raro, pelejando para alterá-la, só o faz enquanto é movido por valores. Estes, por seu turno, repelem os antivalores respectivos" (2002, p.120), quais sejam, a visão conservadora, repressora e violenta expressa em códigos morais. Enfim, esse é o conceito do qual parto para discutir a resistência no cinema del otro lado del río.

A narrativa fílmica argentina, a partir da década de 70, valeu-se dessa linguagem imagética como alternativa para protestar, denunciar e repelir as pautas controladoras do Instituto Nacional de Cine sustentadas por uma ideologia de extrema-direita de mãos dadas com a sociedade mercadológica, misógina, repressiva e dominante. Assim, desenvolveu-se uma produção cinematográfica encorajada pelos militares que tinha por objetivo mostrar o "outro lado", o lado "limpo e familiar" da sociedade argentina em filmes como os de Palito Ortega apropriando-se de valores que atingissem o espectador de maneira positiva, que melhorassem a imagem da ditadura perante a sociedade e a crítica externa. Nesse sentido, a censura, a repressão, o exílio e o desaparecimento de cineastas contrários ao regime abriram caminho para uma produção cúmplice com a triple $A^{2}$ muito semelhante a nossa famigerada Tradição, Família e Propriedade, conhecida como TFP sustentada pela ideologia militar brasileira dos anos 60 e 70.

Rapazes de cabelos compridos apareciam nas telas como terroristas, guerrilheiros, pertencentes ao "eixo do mal" em filmes como Los drogadictos de Enrique Carreras, produzido em 1979 ou em Brigada en acción de 1977 do já mencionado Palito Ortega além de respaldar comédias que enalteciam os valores familiares e religiosos. Não obstante, durante o período ditatorial argentino, a produção cinematográfica contrária ao regime destacou-se por dois eixos fundamentais como forma de protesto e denúncia.

O primeiro deles foi a questão da memória. Embora hoje já se discuta, em se tratando dos anos 60, 70 e 80, o quanto essas décadas, nas palavras de Beatriz Sarlo (2007) "foram décadas ideológicas" (p.62), não temos como negar o que de fato houve, independente da visão política de cada um de nós. Não se trata de julgar A ou B em suas concepções partidárias, mas de reconhecer que a violência extrema foi aplicada com uma severidade e crueldade jamais imagináveis a jovens estudantes tanto do secundário como universitários, intelectuais, pessoas idosas e para horror maior, a mulheres grávidas e a bebês. Nesses termos, podemos entender a filmografia argentina pelos olhos do passado como uma resistência à ditadura da época.

\footnotetext{
${ }^{2}$ Alianza Anticomunista Argentina.
} 
Os filmes produzidos durante e depois da ditadura, põe o dedo na ferida no sentido de manter viva a memória do que ocorreu naqueles anos, transformando-se em lugares simbólicos de memória e de resistência. Lembrar, e também opor-se ao apagamento de uma história que uma parte da sociedade argentina quer esquecer, seja porque esteve diretamente ligada ao Proceso de Reorganización Social, como denominaram as forças que atuaram pelo lado da direita, seja porque esta mesma sociedade se beneficiara de alguma forma com o regime, é tarefa fundamental para a história da Argentina. É interessante pensar sobre quais pilares se constrói a história desse país e até onde ela tem o poder de manter uma memória, ou se é, como se suspeita, uma história que se constitui por seus vestígios. Assim como a passeata semanal das Madres de la Plaza de Mayo, cuja edição já chega a 2014 caminhadas, o conjunto de filmes contra a ditadura se caracteriza como uma memória ferida, evocando através das imagens originais da época, numa mescla de ficção e realidade, uma memória ao mesmo tempo individual e coletiva, complementando-se, como se fosse uma retroalimentação mental. Como escrevera Maurice Halbwachs (2006) a respeito da memória coletiva vista como "uma corrente de pensamento contínuo, de uma continuidade que nada tem de artificial, que retém do passado senão o que ainda está vivo ou é capaz de viver na consciência do grupo que a retém" (p.102), a exibição desses filmes resgata um dever de memória em tempos de fugacidade e a confronta com a história oficial, que por sua vez, explora este período selecionando e hierarquizando o que deve ser lembrado, como praças, monumentos e outra infinidade de signos cuja aproximação com a ditadura convivem hoje, se não de maneira conivente, pelo menos de forma indiferente em relação a um passado sufocado.

O segundo eixo que sustentou a produção fílmica foi justamente a questão da resistência aplicada como conceito moral. Para além do desolvido, termo cunhado pelo uruguaio Fernando Aínsa (2010), a resistência representou uma oposição à Triple A. A denúncia, a recordação e a inconformidade com a situação política da Argentina muitas vezes de forma metafórica em vários filmes, quando a maioria dos diretores viveu aquelas décadas infames e preferiram produzir filmes que não mostrassem cenas explícitas de tortura, mas aludissem a elas de maneira indireta ou velada observando-se que, via de regra, os censores não detinham um alto grau de cultura. Na verdade, os filmes argentinos, em geral, significam muito mais para um público menos global e, sem dúvida, ainda seguem produzindo sentidos na população do país dada a recepção a esse tipo de filme.

A resistência de cunho moral aparece, por exemplo, em La historia oficial, dirigida e escrita por Luiz Puenzo em 1985 e cuja temática é a descoberta, por parte da esposa de um empresário, que sua filha era uma das bebês sequestradas de uma ativista política de esquerda após o parto na prisão clandestina. Esse filme ganhou o Oscar de melhor filme estrangeiro em 1986. Em 18 de março de 2016, o elenco reuniu-se em Buenos Aires na véspera da reestreia para lembrar os 40 anos do golpe militar na Argentina. Norma Aleandro, a atriz principal, afirmou, por ocasião de uma entrevista naquela noite, que sentira muito medo e permanecera tensa ao filmar já que os militares ainda estavam no poder. Além disso, a mãe da criança que interpretava o papel da menina roubada, recebera ameaças de morte, de forma que todos decidiram dizer à imprensa da época que já haviam terminado de filmar, porém, seguiram de forma clandestina. Considerado um dos primeiros filmes produzidos totalmente na Argentina após a queda de Leopoldo Galtieri, a película explora de maneira clara e franca, a visão alienada de uma sociedade preocupada com seu bem-estar e poder, ignorando o clamor dos estudantes, das Madres de la Plaza de Mayo apelidadas pela ditadura de Las Locas e dos intelectuais, entre tantos outros segmentos da sociedade argentina.

O filme explora como a tensão, paulatinamente se instala entre o casal, e vai desvendando o momento político atual. Há um clima de desconfiança e angustia entre Alicia, mãe de Gaby, a menininha adotada, e o pai, Roberto. O traço de ternura nas cenas familiares contrasta com a violência da verdade revelada aos poucos até chegar à última cena com a agressão física por parte de Roberto à Alicia. La historia oficial projeta a resistência ao regime autoritário, lembrando aos 
espectadores o terror da ditadura. A atriz principal, Norma Aleandro, teve que exilar-se no Uruguai e depois na Espanha, após as filmagens.

Recorrendo a Bosi mais uma vez, "a escrita trabalha não só com a memória das coisas realmente acontecidas, mas com todo o reino do possível e do imaginável” (p.121). O filme, fundamentando-se numa realidade que se tornara prática comum dos paramilitares - o sequestro de bebês recém-nascidos na prisão durante as torturas de suas mães - recorre à voz de uma das personagens, amiga de Alicia, para denunciar as torturas sofridas durante sua permanência num dos centros de detenção em Buenos Aires, assim como a conversa que teve com uma das madres cujo teor leva Alicia a ter a certeza que Gaby era, na realidade, filha dessa mulher. Dessa forma, sutilmente, o diretor deixa para o espectador a tarefa de imaginar como de fato as coisas aconteciam naquela época.

Se em La historia oficial a crueldade com os militantes é apenas sugerida, em La noche de los lápices (1986), produzido por Héctor de Olivera, baseado no livro homônimo de María Seoane e Héctor Ruíz Núñez, a violência é explícita a partir da cena em que os alunos do ensino secundário e universitário reunidos em protesto contra o aumento das passagens estudantis, frente à Universidad Nacional de La Plata, são agredidos pelas forças militares. A partir de então, o restante do filme expõe cenas extremamente violentas vivenciadas pelos jovens estudantes no Pozo de Banfield, um dos lugares escolhidos para torturas.

Vale destacar que La noche de los lápices foi amplamente divulgado e reconhecido como um libelo de resistência não só da classe estudantil aos desmandos do governo argentino, mas também, e principalmente, por parte da comunidade cinematográfica, assim como a sociedade classe média e baixa da cidade de La Plata fora agredida com esse ato brutal. Se fazia necessário denunciar, protestar e, acima de tudo, resistir. Os autores do livro haviam realizado uma pesquisa criteriosa, baseada em entrevistas, documentos e testemunho do único sobrevivente, Pablo Díaz, sobre os fatos ocorridos em La Plata. Um filme sobre o sequestro, tortura e desaparecimento de sete jovens estudantes secundários lançaria à luz, três anos depois, como tudo acontecera. Para que jamais a ignominiosa ação fosse esquecida, um ato de resistência, caracterizado como um dos lugares de memória perpetuou-se numa das paredes do saguão da universidade com a imagem gigantesca de cada um dos estudantes desaparecidos. Até hoje suas mães os buscam junto ao governo argentino.

À exceção da ESMA - Escuela de Mecánica de la Armada, (se consegue vê-la de longe ao irse a caminho do Aeropuerto de Ezeiza), a repressão argentina costumava escolher lugares menos óbvios e cujas fachadas aparentavam normalidade como escolas, clubes e garagens.

O filme, Garage Olimpo (1999), com cenas rodadas na Itália durante o exílio do diretor, de 1999, dirigida por Marcos Bechis, trata do sequestro e tortura de María, uma jovem considerada subversiva por ensinar a ler os adultos dos bairros mais pobres de Buenos Aires. Foi vencedor de vários prêmios nacionais e internacionais com melhor direção, melhor roteiro e melhor filme e escancara toda a crueldade do terrorismo paramilitar do governo Videla sem mostrá-la realmente. A câmara se movimenta pelas cenas que o espectador "pressente" a tortura. Sugere o terror da vítima, mas não foca o corpo sendo torturado. Nesse sentido, as cenas insinuam mais do que expõem a vilania da ditadura.

Como este também é um filme baseado em fatos reais, (e em geral os filmes argentinos com essa temática se apoiam na realidade vivida por todos), assim como a grande maioria dos diretores cinematográficos da época, Bechis tinha como objetivo denunciar e resistir a qualquer forma de ditadura. Ao expor a ferida aberta sobre os desaparecidos, ele focaliza a ausência como um valor ético, dando-lhe uma invisibilidade estratégica na última cena ao tratar dos vuelos de la muerte. Soube-se depois, que o vestido usado pela personagem María durante o voo mortal, pertencia à Adriana Silvia Boitano, estudante da Facultad de Filosofía y Letras de la UBA, detida e desaparecida em 24 de abril de 1977. Sua mãe, Ángela Boitano, num ato de amor extremo, emprestou-o à produção do filme. Resistir mostrando o que não está mais visível, contar o que se tentou silenciar, o 
vestido recupera como um dos lugares de memória, tanto de ordem material como simbólica. Material porque a vítima costumava usá-lo e simbólica porque ele presentificava a época e a própria María.

Em Kamchatka, uma produção totalmente argentina de 2002, na qual o diretor, Marcelo Piñeiro "explora o terrorismo de Estado por meio do olhar de um menino de dez anos de idade" que, em 1976, no auge da ditadura, fugiu com a família para um sitio emprestado por amigos. Retrata como temas centrais, a angústia, o medo, a vulnerabilidade, a incerteza, a insegurança e a permanente necessidade de esconder-se. Suzana Kaiser (2010), ao escrever sobre o clima de perseguição instaurado na Argentina nos anos 70, esclarece: A quienes vivimos en Argentina durante aquellos años nos resulta fácil entender por lo que pasa la familia. No hay lugares seguros, amigos y conocidos continúan desapareciendo, circulan rumores sobre las atrocidades que se están cometiendo (p.111). Piñeiro destaca o simbólico da situação p'por meio de um jogo, no qual, o pai, militante da esquerda, costumava brincar com seus dois filhos, o TEG (Tácticas y Estrategias de Guerra). Kamchatka era o último lugar de salvação de um ataque. Este jogo empresta o nome ao filme, convertendo-se na metáfora da resistência ao terrorismo de Estado; isto é, na imaginação do menino, Kamchatka e o sitio se reduzem a um único lugar onde a família pode ao mesmo refugiar-se e enfrentar a ditadura.

A memória do regime é uma presença constante na filmografia argentina e tal presença se entende muito bem quando sabemos que ainda existem entre 14.000 e 30.000 desaparecidos; os órgãos estatais e as organizações como o CONADEP e as não governamentais discordam entre si sobre o número exato. Como não há corpos, a ferida continua sangrando; isso se comprova na produção de filmes desde que a ditadura cívico- militar tomou o poder e mesmo após o seu final em 1983; porém, independente de quem esteja no governo agora, passados 34 anos, esse luto, se traduz em obras fílmicas como a última produção cinematográfica de Sebastián Borensztein: Kóblic (2016) cuja história se ambienta em 1977, um dos anos mais sangrentos da ditadura.

Tomás Kóblic, oficial da Armada, pilotava os aviões que levavam os prisioneiros, alguns sedados, outros não, para o que se chamava, na época, "os voos da morte" pois eram jogados ao Río de la Plata ou ao mar. Atormentado pela consciência, Kóblic deserta e se esconde no pampa argentino como piloto fumigador, o que não impede do comissário Velarde encontrá-lo e obrigá-lo a enfrentar suas lembranças. O filme revela o conflito pessoal que o personagem principal vive em função de uma memória que não o deixa em paz em razão do sentimento de culpa por ser conivente com aqueles assassinatos. Essa deserção se configura como uma resistência a uma lembrança que o acusa diariamente sobre sua responsabilidade daqueles que se encontravam nas mãos dos militares.

Por outro lado, o fato de, em pleno século XXI, um diretor argentino produzir um filme sobre o tema, expressa também uma resistência a todo um sistema que induz ao silenciamento da infâmia institucionalizada e organizada, na qual todos os personagens são "humanamente malos...lo único que es inocente viene a ser la perra", segundo o próprio diretor. Kóblic é um personagem ficcional, contraditório atuando num fundo não ficcional como é o caso da ditadura em si mesma.

Poderíamos seguir noite adentro falando sobre o cinema argentino que aborda a ditadura sob diferentes vieses, como por exemplo, Iluminados por el fuego (2005) e ganhador do $53^{\circ}$ Festival Internacional de San Sebastián, melhor filme XXVII Festival de Cine de Habana e o Prêmio Goya de Melhor Filme Estrangeiro de Língua Espanhola na Espanha em 2006. A trama aborda a participação da juventude argentina na guerra contra a Inglaterra em 1982. Os jovens praticamente foram forçados pelo governo de Videla a lutar contra as forças de Margareth Tatcher nas Ilhas Malvinas; Crónica de una fuga (2006), dirigida por Israel Adrián Caetano, "um reconhecido diretor do chamado "novo cinema argentino", também baseado no livro de Claudio Tamburrini - Pase libre: la fuga de la Mansión Seré no qual descreve as experiências que viveu como desaparecido até sua fuga em 1982. 
E há mais, muito mais para falar-se sobre o terror de Estado. Não obstante uma parte da sociedade argentina alimente a ideia de que o tema já foi tratado em demasia, o interesse sempre surge cada ano, empurrado pela memória até o presente, numa permanente resistência ao esquecimento. Em suma, o valor ético e o estético colaboram, nesse caso, para impedir o esquecimento que, por sua vez, opera na consciência dos que vivenciaram o autoritarismo argentino naqueles anos. Como escrevera Nietzsche certa vez: somente o que não cessa de fazer mal permanece na memória.

\section{REFERÊNCIAS}

AÍNSA, Fernando. Los guardianes de la memoria. Amérika. Disponível em: http://amerika.revues.org/1442?lang=pt. Acesso em 28/08/2017.

BOSI, Alfredo. Literatura e resistência. São Paulo: Companhia das Letras, 2002.

CRÓNICA de una fuga. Produtor: Israel Caetano. Youtube.13/05/2014. 1h43min38s.Kramer y Sigman Films. Disponível em: https://www.youtube.com/watch?v=wPr8pdKdVuc. Acessoem 30/12/2018.

GARAGE OLIMPO. Direção: Marco Bechis, Produção: Daniel Brumann e Diego Dubcovsky. Argentina. Itália. França: Classic-Disarga-Paradis Film - RAI,1999, 1 DVD.

HALBWACHS, Maurice. A memória coletiva. Trad. Beatriz Sidou. São Paulo: Centauro, 2006.

ILUMINADOS por el fuego. Director: Tristán Bauer. UNSAM. Argentina. California Films. 2005. 1 DVD.

KAISER, Susana. Escribiendo memorias de la dictadura: Las asignaturas pendientes del cine argentino. Revista Crítica de Ciências Sociais. Coimbra: Centro de Estudos Sociais da Universidade de Coimbra, p.101-125. Março 2010.

KAMCHTKA. Director: Marcelo Piñeiro. Youtube. 01/01/2018. 1h45min41s. Patagonik. Disponível em: https://www.youtube.com/watch?v=pFUXQFxNF9M. Acesso em 30/12/2018.

KÓBLIC. Produtor e Diretor: Sebastián Borensztein. Inma Cuesta. Youtube. Argentina. 5/12/2015. 0min38s. Disponível em https://www.youtube.com/watch?v=kAvMIOFVhVA. Acesso em 30/12/2018.

LA HISTORIA oficial. Productor e Diretor: Luiz Puenzo. Youtube.Argentina.22 de jul.2013. 2min38s. Disponível em https://www.youtube.com/watch?v=BibM13-Jd8E\&t=41s. Acesso em $30 / 12 / 2018$.

LA NOCHE de los lápices. Direção: Héctor de Olivera. Produção: Fernando Ayala.Youtube.11 de mar.de 2017. 1h35min32s.Disponível em https://www.youtube.com/watch?v=Nx0k0iTiOVA\&t=2543s, Acesso em 30/12/2018. 
RICOEUR, Paul. La memoria, la historia, el olvido. 2a . ed. Buenos Aires: Fondo de Cultura Económica, 2008.

Recebido em 30 de dezembro de 2018 Aceito em 16 de janeiro de 2019 